\title{
Understanding USDA's enforcement process
}

\author{
Andrew D. Cardon, Matthew R. Bailey \& B. Taylor Bennett
}

Many research facilities have struggled recently to understand changes to the Animal Welfare Act (AWA) inspection and enforcement process. The inspection process historically has emphasized education; inspectors worked with institutions to assure the welfare of the animals in each unique registered research facility ${ }^{1}$. However, the United States Department of Agriculture (USDA) Animal and Plant Health Inspection Service (APHIS) now appears to be following a more rigid enforcement approach, with less latitude for repeated citations and more rapid enforcement actions. As part of this approach, APHIS issued in 2010 an Enhanced Animal Welfare Enforcement $\mathrm{Plan}^{2}$, which included the development of an Inspection Requirements Handbook ${ }^{3}$. The Inspection Requirements Handbook was later added as an appendix to the Consolidated Inspection Guide.

Under the new enforcement plan, inspections of registered research facilities remain the responsibility of the APHIS Deputy Administrator for Animal Care. The inspections are conducted by Veterinary Medical Officers. During these inspections, any noncompliance with the AWA regulations and standards is noted and included on an inspection report. Any subsequent enforcement actions are handled by either Animal Care or USDA's Investigative and Enforcement Services (IES), whose investigators evaluate any noncompliant items (NCIs) listed in the inspection report and prepare case reports. The Inspection Requirements Handbook includes a flow chart outlining the four possible follow-up actions with regard to an NCI.

\section{Four possible enforcement options}

The first option is a 90-day reinspection. This option is generally selected when a facility is making clear progress toward compliance and the inspector found only a few minor NCIs (including only a few repeat NCIs) and no signs of jeopardizing animals, animal health or animal welfare. The facility must have had no enforcement actions within the last 3 years, and the inspector expects the facility to come into compliance. If compliance is not achieved in 90 days, the agency will proceed to other enforcement steps.

The second option is the issuance of an Official Warning Letter (7060), which notifies a person or company of an alleged violation. This notification may be issued with or without an investigation by IES. The reasons for issuing an Official Warning Letter include an inspector finding that a facility is out of compliance after a 90-day reinspection, has multiple Repeat NCIs, has a Direct NCI, has incomplete documentation of a serious NCI, is making slow progress toward compliance or has had no enforcement actions (except 90-day reinspection) within the last 3 years.

The third option is the issuance of a Stipulation: an agreement in which the USDA gives notice of an alleged violation and agrees to accept a specified penalty to settle the matter. The settlement agreement form used by IES requires that the penalty be paid within a designated time frame and states that the payment constitutes a waiver of the alleged violator's right to a hearing and a finding that violations of the law have occurred. Before issuing a Stipulation, IES must conduct an investigation. The investigation links the identification of multiple minor Repeat NCIs, moderate to serious NCIs or Repeat Direct NCIs with a lack of progress toward compliance. These actions have typically been taken with regard to facilities that have had previous enforcement actions or at which animal health and welfare have been compromised.
The final option is prosecution by the Office of General Counsel. A Complaint from this Office gives notice to a facility of a formal allegation of possible violations of the AWA. The Complaint does not mean that the facility is guilty of these violations but serves as a notice that the facility must respond and either agree to the allegations in the Complaint or seek a hearing date before a USDA administrative law judge. The judge issues a Decision and Order, which is based on the evidence presented by APHIS and the facility. The facility has the right to appeal this decision. A copy of the final Decision and Order is posted on the USDA website. This process is initiated after an IES investigation in response to a serious NCI, a Repeat Direct NCI or multiple Direct NCIs, with no progress toward compliance, where animal health and welfare have been compromised, and when the facility typically has had previous enforcement actions.

Research facilities should have in place a proactive, progressive animal care and use program and remain in compliance with the AWA regulations and standards. If issues do arise, responsible individuals must ensure that they have a working knowledge of the inspection process and an understanding of the enforcement process.

1. Cardon, A.D., Bailey, M.R. \& Bennett, B.T. The Animal Welfare Act: From enactment to enforcement. J. Am. Assoc. Lab. Anim. Sci., 51, 301-305 (2012).

2. United States Department of Agriculture. APHIS' Enhanced Animal Welfare Act Enforcement Plan (United States Department of Agriculture, Riverdale, MD, 2010). <http://www.aphis. usda.gov/animal_welfare/downloads/awa/ AWA_Enforcement.pdf>

3. United States Department of Agriculture. Inspection Requirements Handbook (United States Department of Agriculture, Riverdale, MD, 2010). <http://www.aphis.usda.gov/animal_ welfare/2011_Inspection_Guide//9.1\%20 Appendix $\% 201 \% 20-\% 20$ Insp $\% 20$ Req $\% 20$ Handbook.pdf> 